\title{
Humanos e Não Humanos na Antropologia ${ }^{1}$
}

\author{
Sophie Houdart
}

Université Paris Ouest Nanterre La Défense - Paris X, Paris, França

E-mail: sophie.houdart@mae.u-paris10.fr

\section{Tradução: Dalila Floriani Petry}

Université Paris Ouest Nanterrre La Défense - Paris X, Paris, França 


\section{Resumo}

Às margens do lago de Genebra, com $27 \mathrm{~km}$ de diâmetro e localizado a 100 metros abaixo do solo, o Large Hadron Collider (LHC) constitui, atualmente, o maior e mais complexo dispositivo experimental jamais construído. As partículas, aceleradas a 99,9999991\% da velocidade da luz, efetuam 11.245 voltas por segundo no acelerador e entram em colisão aproximadamente 600 milhões de vezes por segundo... Na literatura particularmente abundante que descreve o acelerador e lista os seus incontáveis aparatos, o desempenho técnico é comumente transmitido por uma ambição científica igualmente magistral: o LHC, ao oferecer a oportunidade de uma "viagem nas estruturas mais profundas da matéria", tem por missão "a descoberta de leis fundamentais que regem o nosso universo", e deve permitir elucidar até mesmo "os primeiros princípios que governaram a sua formação". A fim de compreender mais atentamente as questões dessa máquina, a proposta aqui é descrever algumas das operações por meio das quais as partículas e o cosmos tornamse comensuráveis.

Palavras-chave: Física. Escala. Antropologia Simétrica. Cosmos.

\section{Abstract}

As the biggest experimental device in the world, the LHC (Large Hadron Collider), settled half in France, half in Switzerland by the CERN (European Laboratory for Particle Physics), is a machine that accumulates superlatives: 100 meters under the ground, particles are accelerated to $99.9999991 \%$ of the speed of light, execute some 11245 rotations around the loop and collide one with each other about 600 million times per second... The incredible complexity supporting these records has been designed for an even more incredible aim: to provide "a journey inside the deepest structure of matter", to discover "the fundamental laws that determine the behavior of nature", to understand "the first principles that govern the universe", and to provide "insights into the origin of the universes". In order to comprehend what is really at stake with this machine, I will go into the details of some of the operations required to commensurate particles and the cosmos.

Keywords: Physics. Scale. Symmetrical Anthropology. Cosmos. 


\section{Introdução}

Чumanos, não humanos, quase-humanos, quase-objetos, objetos 1 fronteiriços, objetos transitórios... é possível dizer que não falta imaginação à antropologia e à sociologia para tentar descrever, o mais precisamente possível, o que se trama na vida social, o que se inventa a medida dos encontros possíveis e sempre singulares entre um humano e um ser ou uma entidade que esses encontros contribuem, portanto, para nascer. "Não humano": a expressão é descendente, como se sabe, da etnologia na qual ela servia para designar as maneiras, extremamente inventivas, pelas quais os povos do mundo denominavam tudo aquilo que não eram eles mesmos... muitas vezes, os deuses, animais, objetos com os quais fazem sociedade e que contribuíam um pouco para formá-los ${ }^{2}$. Provavelmente não é por acaso que se deve a Bruno Latour, um sociólogo com formação na filosofia (notadamente na filosofia pragmatista), uma formulação sistemática do que são os não humanos, do que eles fazem ou fazem fazer.

Partindo da filosofia, Latour iniciou uma investigação de grande fôlego sobre a Razão ocidental, ele estava, em suas palavras, confrontado com o seguinte problema:

[...] interessando-me a uma questão filosófica, compreendi imediatamente que a filosofia não poderia tratá-la, uma vez que se colocava uma questão, mas sem o método que poderia resolvê-la. [...] A filosofia havia feito um trabalho de idealização, mas era necessário equipar a filosofia com um método empírico, para que, finalmente, essas questões se prestassem à investigação. (Fossier; Gardella, 2006, p. 117-118, tradução nossa) ${ }^{3}$ 
Como se sabe, a primeira investigação sobre a Razão ocidental iniciada por Latour foi àquela do laboratório de neuroendocrinologia de Roger Guillemin. É com essa etnografia que ele se torna um sociólogo descobrindo que com "[...] rito-mito-símbolo, não se vai muito longe em um laboratório [...]" (Latour, 2004, p. 5), e em seguida ele faz das ciências “[...] a primeira incontestável prova [é ele quem destaca] na qual a fragilidade constitutiva das categorias fundamentais da explicação antropológica se manifesta com menos ambiguidade [...]" (Latour, 2004, p. 5-6). Não humano é, portanto, de início a pesquisa que o chama, de certa maneira porque ela torna complexas situações que sempre são simplificadas por não serem observadas. - "Nós somos sempre sobrecarregados por aquilo que fazemos", diz Latour. "Ao não conseguir explicar 'culturalmente' a Natureza, nós liberamos os instrumentos dos dois lados, do lado da multiplicidade [da cultura] e do lado da unidade [da natureza]" (Latour, 2004, p. 6). É a partir desse reequilíbrio, o qual é evidenciado na França, por exemplo, na cadeira de Antropologia da natureza, criada no Collège de France em 2001 e ocupada desde então por Philippe Descola (2001, p.12)," que ganhamos todos ao

[...] considerar a ontologia moderna [...] como uma maneira entre outras de classificar as entidades do mundo em função das propriedades que escolhemos lhes atribuir e não como uma medida absoluta contra a qual deveriam ser mesuradas as variações culturais.

Se a antropologia não para de se povoar com seres inéditos (animais, máquinas instrumentos, instalações artísticas, vírus, robôs...), é preciso contar que o salto é mais radical do que a lista com os novos integrantes nos permite imaginar. Ao reorganizar tão profundamente certo número de categorias (até mesmo aquelas de cultura ou sociedade), a antropologia simétrica priva os antropólogos daquilo que lhes serviu durante muito tempo para estabelecer distinções entre eles e nós e os convida a forjar novas. Se não considerarmos mais as 'representações mentais' ou os 'símbolos' como horizontes explicativos das diferenças culturais, se não recorrermos mais a 'crença' para explicar os fatos religiosos, nos resta inventar outros métodos de descrição e uma nova linguagem para dar conta das situações das quais os an- 
tropólogos são testemunhas. Captar na trama analítica, não que seja fácil de desembaraçar, os não humanos assim como os humanos; os animais assim como os criadores (faço referência aqui aos trabalhos da etnóloga e psicóloga Vinciane Drespret, por exemplo); os doentes assim como os médicos, mas também assim como os medicamentos ou os dispositivos de cuidado; a Virgem assim como os crentes (recupero o formidável trabalho de Elisabeth Claverie, publicado em 2003, sobre as aparições da Virgem) - e atribuir a cada um suficientemente de faculdade de agir, de agência ou potência de agir - para ilustrar: essas são algumas das perspectivas abertas no campo geral da antropologia pela perspectiva simétrica.

Além dessa heterogeneidade, que é provavelmente danoso reduzir tão rapidamente, reabsorvendo-a em um único vocábulo "não humano" (que se apresenta como insuficiente, na opinião do próprio Latour, porque é fundado sob uma negação - os não humanos são aqueles que não são humanos - e também porque ele não dá conta dos modos de existência específicos), a ideia geral, que é uma ideia pragmática que conecta entre elas as pesquisas sobre os não humanos, é a de que nós podemos compreender melhor em que consistem os indivíduos e os coletivos humanos ao explorar as múltiplas relações que esses tem com os tão diversos "não humanos". Esse foi o ponto de partida do livro Humains non humains que nós coeditamos com Olivier Thiery. A análise unicamente das relações entre os humanos, a qual alimentou uma parte importante dos trabalhos em ciências humanas e sociais desde o seu nascimento, não é suficiente para dar conta nem da realidade dos coletivos humanos, nem daquela dos indivíduos humanos uma vez que eles se redefinem parcialmente através das suas múltiplas relações com esses "não humanos" que compõem seus diversos meios. Animais, moléculas, objetos técnicos, divindades, procedimentos, materiais, prédios, todos esses diversos não humanos contam, importam para os humanos, e não de maneira cosmética: as relações que temos com eles são um pouco do que nós somos. Nós fabricamos linguagens, sistemas de signos e símbolos, técnicas que não paramos de utilizar, de melhorar, de reparar e nas quais nos apoiamos para inventar ainda mais; nós fazemos obras de arte que nos "alimentam"; construímos prédios a fim de repousarmos, de protegermos e de vivermos nossas 
intimidades; nós cultivamos e veneramos deuses que nos assustam, nos possuem, nos "regeneram" e ao nome de quem nós nos matamos; nós produzimos conhecimentos científicos ou outras formas de saberes que utilizamos para transformar nossas agriculturas, nossas indústrias e nossos sistemas de saúde; nós aprendemos a coabitar com os animais que amamos, enquanto criamos outros para abater e comer; nós estamos assustados com a ideia de que os ambientes frágeis que nos permitem viver tornem-se insuportáveis e incontroláveis, e não cessamos de lutar contra os perigos, por vezes mortais, que eles guardam. Nós construímos nossas instituições, organizações políticas e mercados econômicos fabricando, utilizando e mantendo as técnicas, processos e arquiteturas que, desde que saibamos garantir o seu bom funcionamento, nos servem de representantes auxiliares para fazer caber todos esses coletivos, enquanto as catástrofes naturais ou certos produtos de nossas próprias tecnociências nos obrigam a reconfigurá-los. Tudo isso não é nada: não somente, como escreve Tobie Nathan, "nós não estamos sós no mundo", mas a realidade humana, envolvida nos ambientes que ela desenvolve e que a ameaça, se diferencia e se consolida, toma consistência através de toda essa atividade que as ciências humanas e sociais podem observar e descrever e, no seio daquelas relações entre humanos e não humanos, desenvolver um papel capital.

Falar de não humanos, mais do que de objetos ou de dispositivos técnicos, é, portanto, considerar que objetos, animais, dispositivos técnicos tem sua própria palavra a dizer na relação e que nada é jamais predeterminado: as pesquisas simétricas, que se multiplicam, mostram que quando um humano encontra um não humano, existem tantas incertezas, dúvidas, indecisões, imprevisibilidades, negociações, margem de manobra, quanto em uma relação entre dois humanos... Frequentemente, nas categorias fixas as quais estamos acostumados, aquilo que se determina (e que resta a qualificar) faz trabalhar, de um lado como de outro, as partes tidas como essenciais. As descrições produzem, assim, muitas vezes, efeitos de desestabilização particularmente interessantes porque na relação entre um humano e um não humano são limites ontológicos, pelo que um e outro se definem essencialmente, que estão em jogo. 
Para a maior parte de nós, antropólogos, que utilizamos ou desenvolvemos a noção de não humanos é, creio eu, o próprio trabalho de campo que apresenta essas questões. E para respondê-las nós precisamos da noção de ontologia ou de presença, precisamos do ser. Nós praticamos uma ontologia pragmática, que mede o âmbito heurístico da intromissão do ser nas descrições e análises dos efeitos que ela produz. No horizonte dessa antropologia estão os mundos aumentados, ao menos mais equilibrados. Mundos mais generosos, menos reduzidos, que nos deixam mais atentos aos canteiros ontológicos a respeito dos quais os humanos se preparam continuadamente para dominar os não humanos ainda flutuantes, vindo, os não humanos, para a ontologia problemática ou em suspense.

\section{0 que Ganhamos quando Falamos mais de Seres do que de Coisas? Da Presença? De Existências? De Criaturas? Quais Deslocamentos são Produzidos a Cada Vez?}

Eu comecei por propostas bastante genéricas que não seriam grande coisa se elas não estivessem ancoradas em pesquisas precisas que permitem, cada uma, testar o escopo. E esse escopo, no que diz respeito à entrada por parte dos não humanos, é inicialmente, a meu ver, metodológico. Ele nasce do interesse dado àquilo que interessa as pessoas- estar interessado por aquilo que é na verdade, e não pelo que representa. Escolherei uma das últimas pesquisas que realizei sobre o grande acelerador de partículas do CERN (Centro Europeu de Pesquisa Nuclear).

Ao lado do largo de Genebra e ao sopé das montanhas do Jura, funciona o maior dispositivo experimental do mundo: o Large Hadron Collider (LHC), localizado a cem metros abaixo do solo ele forma um anel de 27 quilômetros de circunferência. Invisíveis a olho nu, partículas circulam em dois feixes em dupla direção e se colidem a 99,9999991\% da velocidade da luz, efetuando 11.245 voltas por segundo em torno do acelerador e entrando em colisão aproximadamente 600 milhões de vezes por segundo. Por si só a eloquência desses grandes números deixa sem palavras todo observador comum na frente dessa máquina experimental extraordinária... Na literatura particularmen- 
te abundante que descreve o acelerador e lista os seus incontáveis aparatos, o desempenho técnico que constitui a construção dessa infraestrutura experimental excepcional é comumente transmitida por uma ambição científica igualmente magistral: o LHC, oferecendo a oportunidade de uma "viagem nas estruturas mais profundas da matérias", tem por missão "a descoberta de leis fundamentais que regem o nosso universo", e deve permitir elucidar até mesmo "os primeiros princípios que governaram a sua formação". É impossível não nos sentirmos tocados - e também deliciosamente oprimidos... - pelo que se passa aqui, especialmente desde que a máquina parece ter cumprido, em julho de 2012, o que se esperava dela desde a sua concepção: a descoberta do Bóson de Higgs, a partícula que faltava para explicar a estabilização do nosso universo.

Para explicar a extraordinária implicação da física e dos físicos nas nossas sociedades atuais, a antropóloga americana Sharon Traweek recorreu, já em seu estudo comparado de laboratórios de física de partículas (Estados Unidos, França, Japão, URSS) que data de meados de 1970, a pelo menos dois tipos muito diferentes de razão: inicialmente, a organização, primeiro (a capacidade dos físicos de se organizarem em comunidades com grandes interesses, facilmente representáveis diante das instâncias de decisões internacionais); o poder emocional da cosmologia (Traweek, 1988), em seguida, o que confere tanto aos físicos, quanto aos não físicos uma aura digna de heróis prometeicos em busca da verdade sobre os mistérios do universo: os físicos

[...] dão notícias de um outro mundo: escondido mas estável, coerente e incorruptível. [...] A dimensão e os custos extraordinários da maior parte dos equipamentos da física vem reforçar o valor cultural [desse evangelho]. Os grandes aceleradores, por exemplo, são como catedrais medievais: livres dos constrangimentos de uma análise em termo de custos e benefícios. (Traweek, 1988, p. 2)

O LHC como catedral dos tempos modernos: era preciso exatamente isso para acolher a aparição do Bóson de Higgs, também chamado de "a partícula de Deus" 4 ... A imagem de catedral é recorrente e circula perfeitamente bem mesmo entre os físicos, engenheiros, gerentes de construção, jornalistas e sociólogos. Como os seus congê- 
neres medievais, o LHC ofereceria um meio de conectar-se à imensidão e aos mistérios do universo, de acessar alguma coisa que nos excede enormemente e que, portanto, nos contém - a expressão moderna de uma transcendência. À maneira dos sábios e astrônomos da Idade Média, os físicos do CERN trabalham atualmente com a ideia de que o macrocosmo, o universo tal como o conhecemos hoje, já estava contido no "microcosmo primordial", na sopa de partículas elementares, ao mesmo tempo que essas partículas já evoluíam elas mesmas em qualquer coisa que se assemelhava a um universo. Ao quebrar o núcleo em dois átomos principais, eles desejam "retornar" até o que aconteceu nos $10^{-25}$ segundos depois do Big Bang - um período anterior a matéria estável existir... Máquina do tempo, máquina para unir o microcosmo e o macrocosmo - os encarregados do LHC não poderiam ter encontrado um terreno mais propício do que esse pedaço do Pays de Gex, na fronteira entre a França e a Suiça, encravado entre o Lago de Genebra e o Maciço do Jura. O poeta William Blake tinha razão: "as grandes coisas são realizadas onde os homens e as montanhas se encontram".

Mas ao seguir muito prontamente as representações do LHC, para que ele serve, nós nos encontraríamos também muito prontamente na incapacidade de compreender precisamente o que se passa no LHC, com o LHC. É que tais equivalências não deixam nenhum espaço para a compreensão, por exemplo, do LHC como "complexo simbiótico" (Beech, 2010, p. viii), que responde melhor à experiência manifestada por aqueles que trabalham com o LHC. Eles, os físicos, engenheiros, operadores, descrevem mais voluntariamente a máquina como uma entidade que se adorna com propriedades de um quase-vivente (Grimaud, 2011). Assim, reconhecemos que ela se mexe, que possui suas próprias pulsações, às vezes dizemos mesmo que ela respira e mais frequentemente que ela se dilata e se retrai, que ela sobe ou desce - e nos esforçamos a cada dia para conhecer um pouco melhor seus pontos fortes e seus pontos fracos. Ao menos, tanto ela é descrita como uma obra que requer alta tecnologia, pelo fato de sua escala e complexidade, ao pensar a prática científica nos termos de um "canal de produção", " a máquina" aparece como um organismo vivente - vivente de uma certa 
vida, podemos dizer - a qual a grande maioria dos físicos e engenheiros procura manter, a todo custo, em um estado estável. Dessa estabilidade dependem duas coisas fundamentais: a produção de feixes "limpos" e "belos" (que tornam qualquer coisa visível); e, resultante desses feixes, a possibilidade de poder sempre distinguir o que se revela como um "ruído de fundo" do que se revela como "sinal" - como um "evento".

A fim de não separar o abstrato do concreto, a cosmologia da experimentação, eu adotei como ponto de entrada não a estrutura social do LHC, mas a máquina ela mesma. As questões que motivaram minha pesquisa foram as seguintes: O que é preciso para ter uma imagem do cosmos? Em qual escala é necessário se colocar para provar (no duplo sentido de sentir e de colocar em prova) que o que está em jogo no LHC é importante para nós? Para responder a essas questões, eu recorri a uma ecologia dos saberes (sobre o assunto, Tim Ingold, mas também Isabelle Stengers). Meu olhar mudou consideravelmente, portanto, no momento em que eu decidi considerar que todo o território do Pays de Gex era o laboratório - que é esse território, até os seus confins e seus habitantes humanos e não humanos inclusos, que estavam alistados, de uma maneira ou de outra, no dispositivo experimental ${ }^{5}$.

Eu ia, portanto, ao CERN para compreender em qual escala se situar para provar (no duplo sentido de sentir e de colocar em prova) que o que está em jogo no LHC é importante para nós ${ }^{6}$. Ao longo das visitas realizadas foram encontrados físicos, evidentemente, mas encontrei também topógrafos, metrologistas direcionais, membros do serviço de meio ambiente e, até mesmo, os juristas porque eu imaginava que alguma coisa se desenvolvia no nível da terra e do território na constituição da física contemporânea. Eu situava assim minha pesquisa levando em conta o que vinculava efetivamente essa máquina extraordinária uma vez que fui acolhida e segui aqueles que asseguravam cotidianamente o seu funcionamento. Então, ao invés da eloquência - que vem e convém naturalmente ao maior dispositivo experimental do mundo -, eu via, ao me situar ao rés-do-chão em algum lugar entre cosmos e partículas, ações insignificantes a serem cumpridas; eu observava tremores maquínicos e vibrações infinitesimais; eu ouvia falar de informações defeituosas, de respirações sutis, que acabavam por dar relevo àquela melancólica planície do Gex... 
Diversos não humanos poderiam ter constituído portas de entrada como primeira escolha para o meu propósito: o pays de Gex, as montanhas do pays de Gex, os javalis ou as vacas (que, acreditem, também tem o que dizer sobre a física contemporânea do LHC...), Deus ele mesmo, a Suíça. Consideremos as partículas. Onde poderíamos nos aproximar dos feixes, das partículas? Como poderíamos nos aproximar sem deixar, no entanto, a diversidade à qual elas são ligadas? Nós estamos no centro de controle central das experiências - um local que se parece muito com uma torre de controle, não era mais do que a vista panorâmica sobre a qual ela abria o interior e não o exterior. É lá onde se configura a máquina e de lá que são orquestrados os feixes de partículas. Os físicos e os operadores "no comando" comparam voluntariamente o seu trabalho à condução de um navio - um "navio espacial do zeptospace" (Giudice, 2010, p. 77). Quando eu ouvi falar deles pela primeira vez foi através de uma física que, contrariamente à divisão fácil que nós tendemos a operar entre físicos e técnicos, distinguia, sobretudo, "os físicos que operam a máquina" e "os físicos que analisam os dados". Para designar os primeiros, ela fala igualmente de "físicos dos aceleradores", àqueles que se ocupam dos grandes detectores, das experiências, que gerem as partículas e fazem "três oitos". A máquina requer, com efeito, funcionar continuadamente, vinte quatro horas por dia, e os "turnos" de oito horas são necessários para a "vigiá-la". O trabalho é descrito como "não exatamente cheio de glamour, é preciso apenas girar um botão!". Mas veremos que ao condutor desse "navio" singular é requisitado haver competências que vão muito além daquelas necessárias para girar um botão ${ }^{7}$. Elas consistem em "homogeneizar", comensurar coisas tão incomensuráveis como os cosmos e as partículas, as "nivelando", "aparando", "sincronizando", todas as operações que tornam compatíveis e funcionais a presença de elementos heterogêneos sobre um mesmo plano ${ }^{8}$. Com os operadores (com exceção dos físicos), podemos aprender coisas inéditas concernentes às partículas e a sua capacidade de se mover em conjunto para informar as estruturas do universo.

Nesse ponto da minha exposição, é preciso ainda ouvir e ver os operadores falarem verdadeiramente sobre o que os preocupa, sobre 
o que direciona sua atenção, os gestos pelos quais eles sinalizam precisamente essa atenção e a compartilham com a máquina ela mesma.

\section{Extrato de Notas - Os Feixes e os seus Navegadores}

São 23h, estou prestes a começar o turno da noite com Georges -Henry no Centro de Controle Central. Nos quatro cantos da imensa sala há ilhas formadas por um quarto de círculo com uma linha de computadores ligados a uma ou duas telas. No alto dessas ilhas, telões exibem medidas. Em cada uma das ilhas, duas pessoas estão em seu turno de guarda.

Um pouco mais tarde da noite, as quatro equipes se encontram em torno da grande mesa central. Servimos suco de laranja e dividimos um tiramisu. O ambiente é intimista. Eu me apresento: "Sophie, antropóloga, eu vim desenvolver uma pesquisa sobre o LHC, sua ligação com o solo, as escalas que é preciso coordenar para produzir uma imagem clara do cosmos". Cada um, por sua vez, diz algumas palavras sobre a sua ilha. Parece que teremos tempo para discutir, a noite se anuncia calma, as máquinas ronronam gentilmente atrás de nós e os feixes alcançaram sua velocidade de cruzeiro. Ao retornar ao nosso lugar na ilha LHC, Laurette me explica que um feixe de partículas contabiliza 1380 pacotes. Nós contamos também em trens, há trens de 144 pacotes e trens de 72 pacotes. E eles produzem efeitos dinâmicos diferentes, eles têm uma granularidade diferente.

Meu objetivo, diz Laurette, é manter as características estáveis no conjunto de feixes. Agora que a máquina está madura, nós tivemos um feedback. Nós trabalhamos com esse feedback para procurar manter os parâmetros o mais constante possivel. Mas, todas as vezes, nós nos perguntamos 'hoje será um dia bom? Um dia ruim?' É como todos os pilotos, nós estamos sempre no mesmo circuito, temos sempre os mesmos carros, mas há apenas um que ganha.

Produzir um bom feixe e o manter estável: é uma questão técnica, mas que depende igualmente de numerosos parâmetros que não são sempre controláveis. É como se os feixes tivessem uma vida própria, e cada uma dessas vidas estivessem irredutíveis juntas. 
Tudo isso, disse-me Laurette, vai depender do histórico, de como foi feito o ciclo magnético anteriormente, por exemplo. E, além disso, não éa mesma coisa injetar ao fim de duas horas ou ao fim de cinco horas. Nós observamos o que se passa ao longo das 24 horas, 'ele se comportou assim, eu posso esperar para ver isso como um problema'. O vácuo também, por exemplo, é tentativa e erro.

No rol do que pode fazer uma diferença, os físicos de feixe incluem igualmente o fato de haver participado ou não do período inicial. "Aqueles que viveram isso tem a tendência de executar o passo a passo para alcançar a colisão. Enquanto aqueles que chegam agora serão menos sensíveis a isso, eles não vivenciaram todo o período de testes, as instabilidades", explica Laurette. Pode igualmente fazer diferença o fato de "vir da experiência", ser físico ou ser engenheiro - "eu, diz Laurette, eu estou do lado da máquina". Além disso, há também os imponderáveis. Como sexta-feira, há quinze dias, um cabo elétrico queimou e o injetor saltou. E há um mês, ao longo de trabalhos realizados na rede de superfície, um técnico da cidade deu um golpe de picareta em um cabo. O senhor se saiu bem, ele teve muita sorte, o golpe foi entre o solo e o cabo. Mas a máquina, ela não gostou muito.

E enquanto o tempo passa lentamente... enquanto não acontece nenhum desses eventos possíveis e suscetíveis de advir a todo momento... Laurette e Georges-Henry continuam a evocar essas noites que "não são iguais", essas noites agitadas, caóticas, "noites nas quais é preciso fazer três injeções", por exemplo. "Nós podemos ter picos de vácuo", fenômenos completamente aleatórios pelos quais não há nada possível a ser feito, nós perdemos o feixe sem compreender. Nós testamos coisas, reduzimos a intensidade, mas "às vezes isso não acontece". Georges-Henry e Laurette notam, como que por eles mesmos, que "acontece muito por série": quando um equipamento começa a ter uma falha, nós a veremos por séries. Nós tivemos uma série de alimentações quebrando, agora temos uma série com problemas de vida do feixe. Nós tivemos também uma série com os kickers, os imãs rápidos que servem à sinalização, e que não chutavam mais - e "disso, bizarramente, nós não ouvimos mais falar". Nós tivemos também a série dos UFO "Unindentified Falling Objects" ou "Unindentified Fast Objects", depende, nós usamos os dois nomes. Nós tivemos como que 
pequenas bolhas que caiam sobre os feixes que induziam perdas muito rápidas e os feixes desapareciam. Ninguém jamais entendeu o que se passou. Houve muitas tentativas de explicação e de manipulações para tentar as reproduzir. Isso pode ter sido a poeira, nós nunca soubemos realmente. "Quando nós ligamos a máquina, diagnostica Laurette, isso leva ao limite certo número de equipamentos".

Enquanto nessa noite nada ainda parece querer perturbar a homogeneidade e desestabilizar os steable beams, Laurette me confia: "o meu lance, a minha psicose é de ter uma homogeneidade nos pacotes de prótons. Não é muito científico, mas eu prefiro dedicar tempo à injeção para ter pacotes homogêneos. É experiência". E como nessa noite, não há grandes coisas a serem feitas, Laurette "gosta muito de observar", observar o tempo de otimização entre dois levelings, fazer correlações, verificar regularmente os níveis de perda,

[...] isso ajuda a compreender se há um dump [uma perda dos feixes] depois. É o meu jeito de aprender, observar o feixe. É como você, antropóloga. Exceto que para mim, a ideia é de observar os outros para tentar os homogeneizar. Eu quero ver como o feixe vai reagir a tal situação. O que faz hoje um feixe perder mais que o outro. Ver quais ações nós podemos fazer para melhorar o feixe. É o que podemos tentar. Mas de qualquer forma, é sempre o feixe que tem a última palavra. O papel pode dizer que o feixe deve fazer isso ou isso, mas se a máquina não quiser... esse é o meu lado técnica.

Eis o que eu gostaria de ter colocado em relevo! Terá dias onde "isso passará", e outros onde "isso quebrará", sem que possamos sempre compreender o que se passou. Certas operações, como àquelas que consistem em "ocupar" e "colocar em colisão", tem um ser "bem padronizado", elas não são jamais perfeitamente solúveis em um procedimento. E nada substituirá o conhecimento extremamente fino da máquina, a maneira pela qual ela gosta de ser conduzida, a maneira pela qual as partículas, elas mesmas, gostam de serem injetadas. As diferentes operações articulam parâmetros sobre os quais nós podemos mais ou menos calcular, uma história e uma memória, uma vontade de transmitir. Elas deixam vislumbrar que os operadores operam menos uma máquina com a qual eles não construíram uma relação, à maneira 
do que nós estabelecemos um longo acordo com um "organismo complexo", envelhecendo, tendo saltos de humor e requerendo esforços constantes para ser "compreendido" (Knorr-Cetina, 1999, p. 116-120). Mais importante ainda: a maneira como eles entram em relação conta, ao final, para compreender como o cosmos, esse outro não humano herói da minha tarefa, se obtém. Nenhuma "representação" do cosmos não disputa, na minha opinião, com o cosmograma formado pelo conjunto de práticas através dos quais os humanos conscientes se aliam à concorrência dos não humanos tão diversos como as partículas, a montanha do Jura, peças de detector, um túnel etc. É somente ao longo dessas composições que estão sempre a fazer, estabilizar, manter, que eu compreendo plenamente ao que o LHC me concerne. O LHC não é uma máquina desconectada do nosso universo. Por mais incomensurável que ela pareça, o que ela trata - a nascença e a composição do cosmos - é sempre ligada de mil maneiras ao lugar que a acolhe e a investe. É uma "máquina romântica", seguindo os termos de John Tresch (2012, p. 12), que se reconhece pelas "fusões e propriedades de troca [que tem lugar] entre os humanos e os seus instrumentos".

\section{Notas}

1 N.T.: Texto apresentado no II Seminário Mapeando Controvérsias Contemporâneas: Simetrização, hibridismo e agência na Antropologia, realizado na Universidade Federal de Santa Catarina (UFSC), no dia 17 de novembro de 2014. Traduzido com a gentil autorização da autora.

2 Para um panorama preciso dessa questão, ver Houdart e Thierry (2011).

3 Todas as citações apresentadas ao longo do texto foram traduções nossas.

4 O nome é na realidade anedótico: Peter Higgs designava pela expressão "the goddman particle" essa entidade inencontrável, a imprensa a transformou em "God particle".

5 Seguindo a constelação terminológica desenvolvida por Vinciane Despret - notadamente Despret (2009) ou por Christelle Gramaglia e Sampaio da Silva (2011).

6 A pesquisa que desenvolvi no CERN entre junho de 2011 e fevereiro de 2012 foi financiada pelo Centre de culture scientifique, technique et industrielle F93, o qual eu gostaria de agradecer aqui. Ela é uma das partes de um projeto coletivo intitulado Propagation de la monotonie ao qual participam igualmente um fotógrafo, Grégoire Eloy, e o artista plástico, Stéphane Sautour. Maiores informações disponíveis em: <http://www.f93.fr/media/Propagation.pdf >.

7 A respeito da condução distribuída de um navio, ver Helmreich (2009) ou Hutchins (1995).

8 Longe de um trabalho de intendência invisível, essas operações são transmitidas 
em grandes telões instalados um pouco por todos os lugares do CERN, nos halls, na cantina, perto das salas de conferências. Todos, ao longo de seus percursos diários que os levam de um ponto ao outro do CERN, podem ver, em tempo real, as curvas da vida dos feixes.

\section{Referências}

BEECH, M. The Large Hadron Collider. Unraveling the Mysteries of the Universe, Springer, New York, Dordrecht, Heidelberg, London: Springer Science + Business Media, 2010.

CLAVERIE, E. Les guerres de la Vierge. Anthropologie des apparitions. Paris: Gallimard, 2003.

DESCOLA, P. Leçon inaugurale de la chaire $\mathbf{d}^{\prime}$ anthropologie de la nature. 2001. Disponível em: < http:/www.college-de-france.fr/media/ pub_lec/UPL52665_LI_159_Descola.pdf >. Acessado em: 10 nov. 2014.

DESPRET, V. Penser comme un rat, Versailles: Editions Quae, 2009. FOSSIER, A.; GARDELLA, E. Entretien avec Bruno Latour. Tracés Revue de Sciences Humaines, [S.1.], n. 10, 2006. Disponível em: <http://traces.revues.org/158>. Acesso em: 10 nov. 2014.

GRAMAGLIA, C.; SILVA, D. Sampaio da. Des mollusques pour «faire parler» les rivières? In: HOUDART, S.; THIERY, O. (Org.). Humains, nonhumains. Comment repeupler les sciences sociales, Paris: La Découverte, 2011.

GRIMAUD, E.; PARÉ, Z. Quand Les Robots Mangeront Des Pommes. Paris: Pétra, 2011.

GIUDICE, G. F. A Zeptospace Odyssey. A Journey into the Physics of the LHC. New York: Oxford University Press, 2010.

HELMREICH, S. Intimate Sensing. In: TURKLE S. (Org.). Simulation and Its Discontents. Cambridge: The MIT Press, 2009.

HOUDART, S.; THIERRY, O. Humains, non-humains. Comment repeupler les sciences sociales. Paris: La découverte, 2011.

HUTCHINS, E. Cognition in the Wild. Cambridge, Londres: The MIT Press, 1995.

KNORR-CETINA, K. Epistemic Cultures. How the Sciences Make Knowledge, Cambridge (Mass.) and London: Harvard University Press, 1999. 
LATOUR, Bruno. Le rappel de la modernité - approches anthropologiques. In: Ethnographies.org, (on-line), n. 6, 2004. Disponível em: <http://www. ethnographiques.org/2004/IMG/pdf/ArLatour.pdf>. Acesso em: 10 nov. 2014.

TRAWEEK, S. Beamtimes and Lifetimes. The World of High Energy Physicists. Cambridge, London: Harvard University Press, 1998.

TRESCH, J. The Romantic Machine. Utopian Science and Technology After Napoleon. Chicago, London: The University of Chicago Press, 2012.

Recebido em 25/08/2015

Aceito em 05/1 1/2015 